\title{
The Medical and Welfare Service for the Elderly in China
}

\author{
Rehabilitation Center, Hebei Provincial People's Hospital (PRC) Qu Lei
}

\section{Demographics of China}

The population of China is 12.9 hundred million, which is the largest in the world: $7.5 \%$ is over 65 years old and about $10 \%$ of the elderly is over 80 years old. One fifth of the elderly all over the world and one half in Asia live in China. China is an aging society now. The natural life expectancy of Chinese people was just 35 years old in 1935 and 57 in 1957. In 1981 the mean life was 67.9, and in 1990 it was 68.6. In 2000 it was 71.4, which has doubled since 1935. In Jan 2004, the anticipating life span of people in Beijing is 79.6.

Generally, it is poverty that is connected with ephemerality. There are more than seventy countries in the world that have become aging societies, but it is only China and three Caucasian countries (Armenian, Georgian and Moldavian), which are developing countries. The other aging societies are all developed countries. The mean GDP in China is only $1 / 30^{+}$of Japan and the United States. As a result, the gray-headed population has already become a great burden to China.

The physical fitness of the elderly in China is similar to other countries, such as being overweight and lacking exercise. Among the 1.26 hundred million people over 60 years old, about $70 \%$ are suffering from geriatric diseases. The mean diseases that each elderly person is suffering from are seven. In some people, the diseases are as many as 25 . About 18 million, that is, $15 \%$ of the elderly, cannot take care of themselves. And $1.2 \%$ of the elderly are bed ridden. About $43.4 \%$ have falls. About $22.1 \%$ have urinary incontinence and $5.1 \%$ have dementia. The prevalence rate of chronic diseases is 3.2 times of all the population, and the disability rate is 3.6 times of all the people. People over 60 are going to spend $2 / 3$ of their time with disease.

The diseases that have the highest incidence rate among the elderly are cardiovascular and cerebrovascular disease, diabetes mellitus, tumor, osteoporosis, depression, and dementia. The disease that has the highest mortality is malignancy in recent years. The others are cerebrovascular disease, respiratory system diseases, cardiac diseases, injury and intoxication.

\section{Insurance systems}

From 1951 and 1952, the Labor' s Medical system and Public Medical expense system had been set up. The labors insurance mainly includes workers in the factories belonging to the public. The latter includes the employers of the government and organization. The common point is that the government and their employers paid the cost. Reform has been taken place from 1998, the Basic Medical Insurance System has been set up to all the employers in the city and town. The company one works for and the person himself pay the fee. The person who has joined the insurance has to pay every month. When receiving medical care in outpatient clinic and in admission, only part of the fee has to be paid. By the end of 2003, the medical insurance system has include 108.95 millions people, among 
which 2.918 million who are retired. This medical insurance system is somewhat convenient for the elderly, but because of the insufficiency in financing, rehabilitation treatment and rehabilitation equipment are not included in this system, except for on-the-job injury cases. The medical insurance pays for the rehabilitation treatment of patients with acute stroke for a very short time when they are in hospital. In some developed areas in China, such as Beijing, the medical insurance can pay for 38 of all the 42 rehabilitation treatments. In the countryside, a cooperative medical system is being tried out. The government, the society, and the patient himself pay $1 / 3$ each. It is great progress, but the cooperative medical system does not include rehabilitation treatments. The low-income people in China can get subsidies from the government when they go to the hospital.

\section{Future care of the elderly in China}

The care of the elderly has caught the attention of society and the government. Many caring centers have been set up, but because of insufficiencies of funds, the fee for caring has to be paid personally. The elderly, who have contributed to the founding of the People's Republic of China, received subsidies of about 1.53 million each month from the government. 